\title{
Subclinical Hypothyroidism in Obese South Indian Children
}

\author{
Srinivasan Thiagarajan ${ }^{1} \cdot$ Thirunavukkarasu Arun Babu $^{1} \cdot$ Rajeshwar Balaji $^{1}$
}

Received: 1 February 2019 / Accepted: 11 April 2019 / Published online: 2 May 2019

(C) Dr. K C Chaudhuri Foundation 2019

To the Editor: Subclinical hypothyroidism is a not an uncommon condition and has an incidence of about $2 \%$ in pediatric age group [1]. It is increasingly recognized that obesity leads to rise in levels of thyroid stimulating hormone (TSH). Although the exact mechanism of TSH elevation in obesity is unclear, the role of leptin has been postulated. This TSH surge in obese children does not signify hypothyroidism in all cases [2]. Normograms based on two large population studies from India reported mean and 97th percentile for TSH as 3.17 and 7.5 , respectively $[3,4]$. However, in obese children, there is no such consensus on cut-off levels of TSH to diagnose subclinical hypothyroidism.

We studied the incidence and progression of subclinical hypothyroidism into overt hypothyroidism in obese children and correlation of fT4 and TSH with Body mass index (BMI). This prospective cross-sectional study included 102 children between 5 and $15 \mathrm{y}$ of age with BMI equivalent to more than $28 \mathrm{~kg} / \mathrm{m}^{2}$ of an adult for age and sex, according to Body Mass Index Cut-offs for Screening for Childhood Overweight and Obesity [5]. Free T4 and TSH were estimated at inclusion and for those whose TSH was above $5 \mathrm{mIU} / \mathrm{L}$, repeat TSH was performed at the end of one year follow-up. Among the participants, 87 (85.3\%) had TSH: 0-5 mIU/L (euthyroid levels), $13(12.7 \%)$ had TSH of $5-10 \mathrm{mIU} / \mathrm{L}$ and $2(1.95 \%)$ had TSH of $10-15 \mathrm{mIU} / \mathrm{L}$. There was no correlation between T4 and TSH with BMI. On follow up, among children with TSH between 5 and $15 \mathrm{mIU} / \mathrm{L}$ (13), 11 (84.6\%) had become euthyroid. There was significant correlation between initial TSH and follow-up TSH $(p=0.036)$ for those who had initial TSH between 5 and $15 \mathrm{mIU} / \mathrm{L}$. It is concluded that TSH surge

Thirunavukkarasu Arun Babu babuarun@yahoo.com

1 Department of Pediatrics, Indira Gandhi Medical College and Research Institute (IGMC \& RI), Puducherry 605009, India is common in childhood obesity. There is no correlation between T4, TSH and BMI. For obese children with TSH 5-15 $\mathrm{mIU} / \mathrm{L}$, thyroxine treatment is not routinely required as most children became euthyroid without any intervention. Further large scale etiological studies are needed to understand pathophysiology of thyrotropinemia among obese children.

Acknowledgments Mrs. Poovitha, Statistician, Indira Gandhi Medical College \& Research Institute, Puducherry.

\section{Compliance with Ethical Standards}

Conflict of Interest None.

\section{References}

1. Debmalya S, Moutusi R. Hypothyroidism and obesity: an intriguing link. Indian J Endocrinol Metab. 2016;20:554-7.

2. Shriraam M, Sridhar M. Subclinical hypothyroidism in children. Indian Pediatr. 2014;51:889-95.

3. Marwaha RK, Tandon N, Desai AK, et al. Reference range of thyroid hormones in healthy school-age children: country-wide data from India. Clin Biochem. 2010;43:51-6.

4. Marwaha RK, Tandon N, Desai A, et al. Reference range of thyroid hormones in normal Indian school-age children. Clin Endocrinol. 2008;68:369-74.

5. Khadilkar V, Khadilkar A. Growth charts: a diagnostic tool. Indian J Endocrinol Metab. 2011;15:166-71.

Publisher's Note Springer Nature remains neutral with regard to jurisdictional claims in published maps and institutional affiliations. 